\title{
El Príncipe armado \\ El estudio de la Tricontinental y la OLAS en América latina: una tarea pendiente
}

\author{
The Armed Prince \\ The study of the Tricontinental and the OLAS in Latin America: a pending task
}

Stella Grenat

Doctoranda Universidad Salesiana / Universidad Pablo de Olavide grenatstella@gmail.com

Resumen: En este trabajo presentamos un estado del arte sobre los estudios dedicados a la Conferencia Tricontinental y la Organización Latinoamericana de la Solidaridad (OLAS), realizadas en La Habana, en 1966 y 1967. Considerando a ambas organizaciones como intelectuales colectivos, que tuvieron por objetivo impulsar un programa y una estrategia revolucionarias, ofrecemos un recorrido historiográfico que nos muestra que ambos eventos abrieron un amplio debate en la tradición bolchevique en torno a la "cuestión armada". Frente a la nutrida historiografía sobre la III Internacional y, en menor medida, la IV Internacional, el estudio dedicado a estos eventos resulta exigua, por lo que concluimos en la necesidad de una investigación sobre el tema enfocada en América Latina.

Palavras Chaves: Tricontinental, intelectual, historiografía.

\begin{abstract}
In this work we present a state of the art on the studies dedicated to the Tricontinental Conference and the Latin American Organization of Solidarity (OLAS), carried out in Havana, in 1966 and 1967. Considering both organizations as collective intellectuals, whose objective was to promote A revolutionary program and strategies, we offer a historiographical tour that shows us that both events opened a wide debate in the Bolshevik tradition around the "armed question". Faced with the extensive historiography on the Third International and, to a lesser extent, the Fourth International, the study dedicated to these events is meager, so we conclude on the need for research on the subject focused on Latin America.
\end{abstract}

Keywords: Tricontinental-intellectualhistoriography. 
Desde que Marx y Engels plantearon su teoría de la revolución, señalando la unidad inescindible del conocimiento científico y la acción política, y promoviendo la organización partidaria internacional de los trabajadores, la "cuestión intelectual" (entre tantas otras) atravesó al movimiento socialista a escala global.

El debate estuvo jalonado, naturalmente, por el desarrollo de la lucha de clases, y el triunfo de la primera revolución proletaria y socialista en la "atrasada" Rusia zarista dio impulso a la teoría leninista del partido revolucionario, organismo que combina, en su interior, a la vanguardia obrera y a la intelligentsia socialista (LENIN, 1960 [1902]: $351-533)$.

El desarrollo del movimiento socialista en Europa expandió y desarrolló la teoría marxista, que encontró en Antonio Gramsci a uno de sus teóricos militantes más avezados respecto de la cuestión partidaria. En su análisis, el Príncipe moderno, el Partido, constituye una forma particular de organización política que desempeña el rol de intelectual colectivo (GRAMSCI, 2000 [1984]; 2001 [1984]). Se trata de un colectivo orgánico respecto de la estructura social en la cual se desenvuelve y, mediante la unión del trabajo manual y el intelectual, se constituye en un organizador fundamental de la clase revolucionaria: las diferentes graduaciones de cuadros, oficiales y soldados representan una analogía con la estructura militar de un ejército. Los partidos comunistas de todo el mundo, y la III Internacional (1919-1943) representan la concreción histórica de esta teoría, cuyos fundamentos también fueron tomados por el trotskismo y la IV Internacional.

No obstante, desde mediados del siglo $\mathrm{XX}$, la teoría bolchevique de organización revolucionaria se vio enriquecida, y al mismo tiempo confrontada, por una oleada de revoluciones en una geografía pronto unificada bajo el concepto de "Tercer Mundo", particularmente en China, Vietnam y Cuba (MANSILLA, 1987; ESCOBAR, 2007). En ellas, no sólo el campesinado aparecía como parte de la alianza revolucionaria en la que asumía el papel protagónico, sino que la "cuestión armada" tomó un protagonismo que la diferenció del proceso ruso de principios del siglo XX. Asimismo, se puso en cuestión la forma de organización que debía adoptar el sujeto revolucionario, aunque sin renegar del leninismo, en tanto todas se consideraron parte del universo soviético y abrió una enorme discusión: ¿Partido o Movimiento? ¿Intervención en las masas para volcarlas a la insurrección o conformación de guerrillas / ejércitos para la liberación de territorios y la construcción de doble poder en ellos? 
El debate tuvo su momento álgido en la década de 1960, luego de la revolución cubana, y alcanzó una escala global en 1966, con la organización de un evento internacional que intentó constituirse en una coordinadora de lucha revolucionaria en Asia, África y América Latina: la Tricontinental. Entre el 3 y el 15 de enero de 1966, La Habana albergó en una monumental conferencia que reunió a 512 delegados provenientes de 82 países (197 delegados de Asia, 150 de África, 165 de América Latina), 64 observadores y 77 personalidades invitadas. Las dos semanas de acalorados debates concluyeron en la elaboración de un programa y una estrategia que, en América latina, serían impulsadas por medio de la creación de un nuevo organismo de coordinación, la Organización Latinoamericana de la Solidaridad (OLAS). Se trataba de dos eventos políticos que buscaron darle proyección internacional a esta nueva forma de organización revolucionaria que disputaba su hegemonía quienes otorgaban un rol central al partido. En este sentido, la Tricontinental y la OLAS se constituyeron en intelectuales colectivos de nuevo cuño, rivalizando, en el plano internacional, con la tradición bolchevique de organización internacional, que en aquel entonces buscaba sostener el trotskismo.

Y aunque una nutrida historiografía analizó los derroteros de la III Internacional y, en menor medida, de la IV Internacional, los estudios dedicados a la Tricontinental, en general, y a su historia en América Latina, es decir la OLAS, resulta exigua. En este artículo, presentaremos los antecedentes sobre la cuestión, con el objetivo de mostrar la necesidad de una investigación inédita.

La Tricontinental y la OLAS fueron estudiadas en un (escaso) número de trabajos monográficos, forman parte del relato de un heterogéneo conjunto de investigaciones que tomaron por objeto de estudio otros temas y problemas: historias mundiales, nacionales (principalmente, de Cuba), del socialismo, de América latina, de la Guerra Fría, de los partidos, organizaciones y dirigentes políticos que participaron y un largo etcétera que nos obligan a rastrear la información disponible en diversos estudios.

El estado del arte implica, entonces, no sólo referirse a las monografías y artículos que han tomado como objeto de estudio principal a la Tricontinental y la OLAS, sino también a las investigaciones que, enfocadas en otras cuestiones, presentan resultados o información parcial sobre ambos eventos. 


\section{La Tricontinental y la OLAS: de lo general a lo particular}

Historia global; historia latinoamericana; historia del Tercer Mundo

¿Cuál es el papel de la Tricontinental en la historia del mundo? La lectura de algunos de los principales manuales sobre el tema deja una imagen contradictoria. Aunque la gran mayoría de los libros de historia mundial, global o trasnacional del siglo $\mathrm{XX}$, tanto de los que alcanzaron el carácter de clásicos, como de aquellos que han sido publicado en los últimos años, dedican (en mayor o menor medida) un cierto protagonismo a las luchas y revoluciones de Asia, África y América en la década de 1960, no siempre atienden a su carácter orgánico. En decir, no los presentan como expresión política de un fenómeno estructural ni como parte de una misma organización, prefiriendo el concepto, más vago e incorrecto, de influencia. Ello ocurre, incluso, en historiadores marxistas (comunistas y trotskistas).

Por ejemplo, es sorprendente que la reconocida Historia del siglo XX, de Eric Hobsbawm, no haga mención a la Tricontinental, planteando incluso que la ruptura chino-soviética supuso "el final de cualquier tipo de internacionalismo socialista o revolucionario, puesto que las fuerzas disidentes o antimoscovitas no desarrollaron ninguna organización internacional efectiva, más allá de sínodos sectarios rivales" (HOBSBAWM, 1998: 447). Esta idea, que relega los movimientos revolucionarios que se desarrollan por fuera (o en abierto enfrentamiento) con la Unión Soviética se completa al asegurarse que León Trotsky y la oposición de izquierda "fracasó por completo en todos sus proyectos. Su Cuarta Internacional, que pretendía competir con la Tercera, sometida a la influencia de Stalin, no alcanzó importancia. En 1940, cuando fue asesinado por orden de Stalin en su exilio mexicano, había perdido toda su influencia política" (HOBSBAWM, 1998: 81).

La tesis de Hobsbawm no sólo niega (o ignora) la existencia de la Tricontinental, sino que hace lo propio con el movimiento trotskista en América Latina, obturando cualquier posibilidad de comprender cómo y por qué Fidel Castro polemizó con organizaciones trotskistas en el discurso de cierre de la Tricontinental, o de explicar el origen de algunos de los principales partidos revolucionarios de América latina, que provenían del frondoso árbol del trotskismo, cuyas ramificaciones conducían, 


\section{indefectiblemente, al México de 1940 (SECRETARÍA GENERAL DE LA OSPAAL,} 1966).

Un problema similar encontramos en los dos importantes volúmenes que Josep Fontana dedicó, recientemente, al llamado siglo de la revolución: la ausencia de la Tricontinental también deriva en la tesis de la inexistencia de una acción coordinada entre las guerrillas y movimientos de liberación nacional del proceso revolucionario global (FONTANA, 2013 [2011]; 2017). ${ }^{1}$ Por su parte, tampoco hace referencia a ella Neil Faulkner, que subsume la "teoría de la guerra de guerrillas" y su desarrollo a la voluntad individual del Che Guevara (FAULKNER, 2013: 421-423). Diferente es el balance de Chris Harman, quien no sólo advierte en torno a la Tricontinental y la OLAS, sino que también las caracteriza como un intento por encontrar una alternativa revolucionaria a la URSS y China que, no obstante, fue rápidamente derrotada, en 1968 (HARMAN, 2013). ${ }^{2}$

Algo similar ocurre con las historias generales de América latina, que pasan de ignorar el tema a incorporarlo como un elemento importante del proceso histórico. En el clásico manual de Tulio Halperín Donghi, que aún sigue siendo uno de los más utilizados, el papel de las organizaciones político militares que actuaron en los años '60 apenas es señalado, y no se mencionan la Tricontinental ni la OLAS. En su defensa, aunque la obra fue objeto de más de 20 reediciones, el texto original fue publicado al año siguiente de la Tricontinental, en 1967 (HALPERÍN DONGHI, 2005 [1967]).

En la también clásica Historia de América Latina de la Universidad de Cambridge, es llamativa la ausencia de ambos eventos en el capítulo de Alan Angell, dedicado específicamente a la izquierda en la región (ANGELL, 1997: 73-129). No obstante, aparecen en el dedicado a la intervención política de los militares en la región:

\footnotetext{
${ }^{1}$ En tal sentido, no da cuenta de la existencia del intento cubano por establecer una coordinación política centralizada de los movimientos de liberación nacional. En el caso más relevante, la intervención del Che en el Congo, la presenta como el resultado de una decisión unilateral congoleña: "el Consejo Supremo de la Revolución, dirigido por Gaston Soumialot, pidió ayuda a los cubanos, Ernesto 'Che' Guevara aceptó y viajo al Congo con un pequeño grupo de instructores" (FONTANA, 2017: 358).

2 "En el terreno internacional hubo un breve intento de escapar a las limitaciones impuestas por la política rusa. Los líderes cubanos crearon 'Organizaciones de Solidaridad Latinoamericana' y convocaron a conferencias 'tricontinentales' en las que hicieron críticas a medias veladas de las políticas que Rusia estaba imponiendo a los partidos comunistas y a los movimientos de liberación nacional del Tercer Mundo. El Che Guevara acabó por abandonar Cuba para intentar poner en práctica estas críticas mediante la lucha guerrillera en el Congo-Zaire y en Bolivia. Pero ni las críticas ni la práctica del Che Guevara se basaban en una evaluación concreta de las fuerzas de las clases en una situación particular. Por el contrario, Guevara intentó imponer el modelo de lucha revolucionaria que había tenido éxito en las muy especiales circunstancias de Cuba. La intervención en el Congo se saldó con un lamentable fracaso y la actuación en Bolivia fue dando tumbos de desastre en desastre hasta la muerte del Che: matado a tiros tras ser capturado por un agente de la CIA. En 1968, Castro y el gobierno cubano estaban de nuevo apoyando la posición rusa" (HARMAN 2013: 520).
} 
mientras que la Tricontinental constituiría "una nueva Bandung revolucionaria", la OLAS habría tenido el objetivo de "dar su aprobación oficial a los numerosos intentos de crear focos de guerra de guerrillas en América Latina de acuerdo con la estrategia castrista" (ROUQUIÉ y SUFFEN, 1997: 291-292). ${ }^{3}$

Por su parte, Alain Rouquié considera que las necesidades estratégico políticas de Cuba constituyeron el impulso fundamental para la creación de la Tricontinental, destacando su rol en la consolidación de una nueva fuerza revolucionaria (ROUQUIÉ, 1994 [1987]). ${ }^{4}$

Más recientemente, Waldo Ansaldi y Verónica Giordano, en el marco de un análisis de las grandes revoluciones latinoamericanas y de las organizaciones político militares que actuaron en las décadas de 1960 y 1970, relacionan el apoyo a la estrategia armada a través del impulso de formaciones guerrilleras, el envío de ayuda sanitaria, educadores y técnicos a muchos países de Asía, África y América Latina al despliegue, por parte de la revolución cubana, de una política propia de la tradición socialista: el internacionalismo proletario. Destacando, que esta política fue tomada con independencia de la URSS (ANSALDI y GIORDANO, 2012). Y presentan a la OLAS como un órgano nacido para coordinar la acción de las organizaciones armadas bajo la consigna de alcanzar "la segunda independencia", establecida en la Segunda Declaración de La Habana, de 1962. (ANSALDI y GIORDANO, 2012: 296).

La cuestión de la coordinación entre países y movimientos oprimidos para su liberación ha sido tomada por la historiografía dedicada al estudio del denominado "Tercer Mundo", por lo que la Tricontinental ha sido tenida en cuenta, destacando su

\footnotetext{
3 "El régimen cubano, por su parte, intentó convertirse en un foco mundial de influencia y acción revolucionarias. Así, en enero de 1966 La Habana fue sede de la Conferencia Tricontinental, una nueva Bandung revolucionaria. En julio y agosto de 1967 la conferencia de la Organización Latinoamericana de Solidaridad (OLAS) se reunió en la capital cubana para dar su aprobación oficial a los numerosos intentos de crear focos de guerra de guerrillas en América Latina de acuerdo con la estrategia castrista. Sin embargo, el fracaso en Bolivia de un atrevido intento de convertir los Andes en la Sierra Maestra de América del Sur, intento que concluyó en octubre de 1967 con la muerte de Ernesto 'Che' Guevara, el legendario lugarteniente de Castro, simbolizó el final de un período y señaló el comienzo de la retirada cubana" (ROUQUIÉ y SUFFEN, 1997: 291-292).

4 "Un nuevo eje revolucionario tercermundista y no alineado que une Vietnam del Norte, Corea comunista y Cuba parece ver la luz. Ni la Unión Soviética ni China están representadas en los órganos directores de la conferencia. Estados Unidos además del embargo económico y la malograda la tentativa de invasión mercenaria de Bahía de Cochinos, aprovecha el gran temor desencadenado por el castrismo en América Latina para hacer que se excluya a Cuba de la Organización de los Estados Americanos en Punta del Este, en enero de 1962. Puesta al margen de las naciones latinoamericanas, Cuba responde con la 'segunda declaración de La Habana', que define la vía cubana al socialismo, y lleva la iniciativa revolucionaria a todo el continente. Al ya no tener relaciones diplomáticas con los estados latinoamericanos, excepto México, Castro exportará la revolución tal como la concibe ayudando y entrenando a los grupos armados revolucionarios que se dicen partidarios de su experiencia" (ROUQUIÉ, 1994 [1987]).
} 
capacidad para impulsar un polo de independencia política ideológica y estratégica en el marco del mundo bipolar de la Guerra Fría.

El estudio más completo sobre el tema es el de Vijay Prashad, que ubica la Tricontinental en el entramado de fuerzas de los pueblos de Asia y África que lucharon por liberarse del colonialismo europeo que sobrevivió a la segunda posguerra y por el desarrollo económico y social de sus pueblos (PRASHAD, 2007). Sitúa los orígenes de la conferencia en la reunión de Bandung (1955), que constituiría uno de los hitos fundantes de la nueva "potencia tercermundista" que tomaría un lugar preponderante frente a los bloques que, bajo la égida de EE.UU. y la URSS, se enfrentaban a nivel mundial. En el plano organizativo, en Bandung quedaría establecida la Organización de Solidaridad Afro-Asiática (OSPAA); en Belgrado (1961), el Movimiento de Países No Alineados (MPNAL); y en La Habana (1966), se institucionalizaría la incorporación de América Latina a la lucha por la liberación del Tercer Mundo. Ubicada en esa genealogía, la constitución de la Tricontinental respondería, como decíamos, a la búsqueda por constituir una salida alternativa a las presentadas por las dos potencias de la Guerra Fría.

La cuestión del carácter de esta independencia, que iba desde reestablecer el objetivo socialista frente al reformismo etapista y pacifista soviético, hasta el impulso de una nueva vía (capitalista) de desarrollo económico, nacional y antiimperialista, fue retomada por Germán Alburquerque (ALBURQUERQUE, 2017). ${ }^{5}$ Su tesis de que Cuba mantuvo una distancia política con el tercermundismo ${ }^{6}$, fue retomada por la historiografía global de los '60 que, recientemente, planteó el debate en torno a los objetivos políticos del Tercer Mundo (CHEN et al., 2018: 4). Asimismo, mientras que Obregón esquematizó los enfrentamientos globales entre movimientos antiimperialistas y "Estados anti-comunistas", Barcia estudió el carácter de antiimperialismo norteamericano esbozado por la Tricontinental. (OBREGÓN, 2017: 232-246; BARCIA, 2009: 208-217).

\footnotetext{
${ }^{5}$ Desde su perspectiva, Cuba se reivindicó “de modo simultáneo, miembro del bloque socialista, militante del No Alineamiento, y nación subdesarrollada inserta en la dinámica norte-sur” (ALBURQUERQUE, 2017: 180).

6 "aunque el compromiso de Cuba con el Tercer Mundo fue casi desde el inicio un pilar de su comportamiento internacional, ya sea a través del Movimiento como de la Conferencia Tricontinental y la subsecuente Organización de Solidaridad de los Pueblos de África, Asia y América Latina (OSPAAAL), su imagen del tercermundismo, como concepto, era negativa, pues entendía que carecía de la fuerza política y del poder de transformación que sí poseía el No Alineamiento o las asociaciones de movimientos de liberación revolucionarios vigentes en África, América Latina y Asia" (ALBURQUERQUE, 2017: 181).
} 
Las historias del Tercer Mundo y de los Global Sixties se entrecruzan con aquellas que, con el objetivo de encontrar los antecedentes de las alianzas regionales que actualmente vinculan a América Latina (como el Mercosur y el ALBA), conceptualizan su observable ya no en torno a un polo unido por la opresión (el mundo colonial o semicolonial), ni tampoco tercermundista o tricontinentalista (PITMAN \& STAFFORD, 2009; PRASHAD, 2013), sino por la geografía: la cooperación "sur-sur" o el "sur global" (2015; 2017; 2018).

Desde esta perspectiva, Bermúdez Erazo plantea que la Tricontinental fue parte de la constitución de un espacio de negociación alternativo al promovido por las potencias económicas del norte (BERMÚDEZ ERAZO, 2014). ${ }^{7}$ Desde esta forma, la Tricontinental no es entendida como parte de una política revolucionaria que impulsaba una alternativa al capitalismo, sino como una estrategia de los "países emergentes" y en "vías de desarrollo que buscaron generar espacios de participación y democratización de las relaciones internacionales" (BERMÚDEZ ERAZO, 2014: 31) Asimismo, se plantea que el objetivo de la OSPAAAL, no habría sido la lucha contra la opresión nacional y social, sino la búsqueda de un mayor desarrollo económico en términos capitalista de los países de Asia, África y América Latina.

Pero la genealogía (política, ideológica y estratégica) entre las conferencias de La Habana y Bandung, establecida por los estudios tercermundistas, fue cuestionada por historiadores del colonialismo (FERRO, 2000 [1994]) ${ }^{8}$ y el "postcolonialismo" (YOUNG, 2001; 2005). En este sentido, Robert Young asegura que, en la primera reunión realizada en Indonesia, habría primado la posición defendida, por ejemplo, por el presidente de Egipto, Nehru, para quién, en un mundo bipolar, la mejor defensa para las nuevas naciones era la acción por separado y la no intervención. Esto supondría el extremo de la no intervención en las luchas de los países que aún no se habían independizado. Es decir, que se rechazaba la conformación de una identidad política por fuera de EE.UU. y la URSS, en defensa de una imaginaria identidad neutral. Siempre en esta misma línea, Nasser y Sukarno habrían enfatizado que su principal objetivo era constituirse en una fuerza moral para la paz. Destacando las especificidades político

\footnotetext{
7 "El surgimiento de otros organismos internacionales que están fuera del sistema de Naciones Unidas pero que son importantes en la conformación de nuevos grupos asociativos, así como en la concepción y proyección de la cooperación sur-sur. La Organización de Solidaridad con los Pueblos de América Latina, Asia y África -OSPAAAL- (1966) y el Sistema Económico Latinoamericano y del Caribe - SELA(1975) se constituyen en espacios o mecanismos para promover los principios o fundamentos de la cooperación sur-sur" (BERMÚDEZ ERAZO, 2014: 30).

${ }^{8}$ Marc Ferro equipara la Tricontinental a la Comintern, como organismos que buscaron impulsar y coordinar la lucha revolucionaria de los países coloniales (FERRO, 2000 [1994]: 326).
} 
ideológicas y estratégicas de cada una de estas conferencias, recién en 1961, con la creación del MPNA, se pretendería la constitución de un eje alternativo a las dos grandes potencias: un eje tercermundista. Y habría que esperar hasta 1966, para que, en la Conferencia Tricontinental, se manifestara la alineación a los soviéticos y la reversión del pacifismo por la defensa abierta de la vía armada como la mejor alternativa para la lucha de los países del Tercer Mundo.

Por su parte, Antoni Kapcia plantea que Cuba fue capaz de definir una perspectiva político estratégica relativamente independiente de las dos superpotencias y que la fue llevando adelante, paulatinamente, mucho antes de enero de 1966 cuando logró imponerla en la Conferencia Tricontinental (KAPCIA, 2012 [2008]: 117). Su planteo político alternativo habría supuesto un nivel de radicalidad superior al de la URSS expresado en el llamamiento a que Latinoamérica se sume a la lucha armada para derrotar al imperialismo norteamericano. Este proceso de individualización cubana empezaría a cristalizar muy tempranamente, manifestándose en la primera y segunda declaraciones de La Habana, en septiembre de 1960 y febrero de 1962 respectivamente. Si bien afirma que la Conferencia Tricontinental fue organizada por la URSS, en ella se habría impuesto una línea estratégica cubana, que se distinguiría, como dijimos, por su orientación latinoamericana y su carácter armado. Kapcia insiste en que, a partir 1966, se intensifica el desafío a los soviéticos, sumando el cuestionamiento respecto al sujeto revolucionario en las sociedades del tercer mundo, en ellas no podría verificarse la primacía de la clase obrera como agente revolucionario, sino la de los campesinos y estudiantes.

Un argumento similar es sostenido por Faligot, para quién, lejos de estar subordinada a los soviéticos, como habrían creído los chinos, la Tricontinentale était justement le levier conçu par Fidel, le Che, Piñeiro, Cienfuegos et leurs amis pour éviter cette situation (FALIGOT, 2013: 316). ${ }^{9}$ Asimismo, Priestland destaca la existencia de un margen de acción política cubana que con la OSPAAAL, nacida de la Tricontinental, "Castro quería sustituir el Movimiento de Países no Alineados surgido de Bandung, proclamando que el viejo 'socialismo autóctono' del Tercer Mundo había muerto para reencarnarse en un marxismo más militante" ${ }^{1}$ (PRIESTLAND, 2010).

La Tricontinental y la OLAS: ¿historia de la revolución socialista o burguesa?

\footnotetext{
9 "La Tricontinental fue precisamente la palanca diseñada por Fidel, Che, Piñeiro, Cienfuegos y sus amigos para evitar esta situación" (Traducción propia) (FALIGOT, 2013: 316).
} 
El debate al interior de la historiografía "tercermundista" en torno al carácter de la "independencia" del movimiento de liberación nacional (estrategia socialista vs. Estrategia de desarrollo capitalista independiente) plantea la siguiente cuestión: ¿la Tricontinental y la OLAS constituyen capítulos de la era de la revolución socialista o el capítulo final del largo proceso de revolución burguesa? En tanto las historiografías de ambos procesos se desarrollaron de forma autónoma (como veremos, salvo excepciones), no poseemos una respuesta definitiva.

Por un lado, las historias del socialismo suelen concentrarse en sucesos europeos, relegando el papel jugado por el movimiento en Latinoamérica, lo que resulta llamativo sobre todo al momento de analizar su coyuntura en la década de 1960, cuando la revolución cubana concentró las miradas del universo político (SASSON, 2001). No obstante, aunque la mayoría de los estudios hacen referencia al proceso de la revolución cubana, al papel de las llamadas "guerrillas", a las luchas de liberación nacional, y a Fidel Castro y el Che Guevara en particular, no siempre se clarifica el papel jugado por la Tricontinental y la OLAS (HOBSBAWM, 2018; PRIESTLAND, 2010). Por supuesto, existen excepciones, como la Historia general del socialismo dirigida por Jacques Droz, en la que la Tricontinental y la OLAS ocupan un lugar significativo, en el marco del debate en torno al castrismo como vía alternativa al camino al socialismo impulsado por la URSS y China. En ella, si bien reconoce su fracaso, "en el sentido de desencadenar una crisis general que desembocase en la revolución”, considera que enriqueció al socialismo con los debates que presentó (DROZ, 1986: 347). Por su parte, desde la década de 1970 creció, sistemáticamente, una historiografía que analizó al marxismo "latinoamericano", es decir, los aportes a la teoría revolucionaria presentados por militantes del subcontinente. En una producción muy desigual, sobresale el aporte de Michel Lowy, quien caracteriza a la OLAS como:

la expresión política más elevada de este primer período del castrismo en el continente. La significación histórica de ese congreso se encuentra, en primer lugar, en su tentativa de coordinación continental, por primera vez desde Bolívar, del proceso revolucionario latinoamericano, y, en segundo lugar, en la inequívoca y franca proclamación de unidad de contenido democrático y socialista de la revolución latinoamericana [...] La OLAS 
también tomó una posición a favor de la guerrilla como el método de lucha más eficaz en la mayoría de los países del continente (LOWY, 2007: 49).

Por su parte, desde otra perspectiva teórica, Marta Harnecker vio en la Tricontinental el "primer intento por unificar las fuerzas revolucionarias de tres continentes", señalando, no obstante, que la organización surgida del evento constituyó un medio ineficaz para combatir el imperialismo debido a las divisiones creadas por la polémica chino-soviética, asegurando que la OLAS se reunió una sola vez y terminó desapareciendo por su propia inercia (HARNECKER, 1999).

Asimismo, existe una importante tradición historiográfica dedicada a estudiar la historia de las organizaciones armadas en América latina, las que han señalado el papel de la Tricontinental y la OLAS (TORRES MOLINA, 1968; GUILLÉN, 1969; GOTT, 1971; GONZALEZ, 1984; GILLY， 1986; WICKHAM-CROWLEY， 1992; CASTAÑEDA, 1993; GASPAR, 1997; PIÑEIRO; 2001; ROT, 2000). El estudio más completo continúa siendo el de Daniel Pereyra, quien considera que el impulso a las guerrillas en la década de 1960 estuvo estrechamente vinculada al mensaje del Che Guevara a la Tricontinental, así como en el impacto diferenciado de la OLAS en las diversas organizaciones latinoamericanas (PEREYRA, 2011). Recientemente ha incursionado en la cuestión Aldo Marchesi, quien presentó una completa visión de conjunto de la historia de las organizaciones armadas latinoamericanas, atravesada por el papel jugado por la Tricontinental y la OLAS (MARCHESI, 2017; 2019).

De hecho, la "cuestión guerrillera" ha sido objeto de análisis, en particular, para los intelectuales de la fuerza social contrarrevolucionaria que combatieron a la “subversión marxista internacional” (PIEHL, 1966). ${ }^{10}$ En la Argentina, aunque existían cuadernos de formación militar que trataban la cuestión de la guerrilla y la izquierda, los esfuerzos más elaborados se produjeron en el marco de la post dictadura, desde mediados de la década de 1980. En esa etapa, los militares establecieron la filiación político ideológica internacional de lo que denominaron "guerra revolucionaria argentina", la que habría formado parte de un conflicto mundial en el cual las "fuerzas subversivas" de cada espacio nacional responderían a las órdenes de la URSS, en su lucha por extender su dominio a nivel mundial. Para cumplir este objetivo, se

\footnotetext{
${ }^{10}$ En este sentido, resultan paradigmáticas las tesis producidas en la Escuela de Guerra de la Armada norteamericana, redactadas al mismo tiempo en que se desarrollaban los hechos, y constituían un esfuerzo teórico por "conocer al enemigo", dando cuenta de la proyección política de Cuba y China en América Latina. Véase (PIEHL, 1966).
} 
adiestrarían "agitadores y guerrilleros, tanto en la URSS como en sus satélites: Cuba, Checoslovaquia, Corea del Norte, etc. Normalmente la ruta pasa por París, [...] desde donde llegan a Praga sin que se registre ese movimiento en sus pasaportes" (DÍAZ BESSONE, 1986: 58).

Siguiendo este argumento, se vincula la acción de organizaciones político militares argentinas con la Tricontinental y la OLAS, retomando las resoluciones editadas en su "Proclama final". ${ }^{11}$ Es destacable el conocimiento de las diferentes organizaciones de izquierda que se manejan en este trabajo, que incluye una mención a la influencia de la IV Internacional en la Argentina. ${ }^{12}$

Pero la naturaleza de los eventos que analizamos posee un carácter tan complejo y contradictorio que, mientras que un conjunto de historiadores (la mayoría, de hecho), considera que las luchas de los pueblos del tercer mundo, en general, y las revoluciones en China, Vietnam y Cuba, en particular, son parte de la era de la revolución socialista, también han sido consideradas como nuevos episodios de la revolución burguesa.

En este sentido, Neil Davidson caracteriza que, en Cuba, "después de 1959, fuerzas externas o internas sustituyeron un modelo de capitalismo por otro" (DAVIDSON, 2013: 878). Rechaza, entonces, el carácter socialista u obrero de los Estados constituidos cómo resultado de la victoria de estos movimientos de liberación nacional y considera que ellos no pueden ser clasificados a partir de su subjetividad, dado que:

raramente se presentan como revoluciones burguesas, y una de las razones es que $[\ldots]$ había surgido una forma extraordinaria de falsa conciencia

\footnotetext{
${ }^{11}$ En el caso argentino, se establece que "la República Argentina fue teatro de una guerra revolucionaria que comenzó a gestarse a partir de 1956, mostró sus primeras evidencias en 1959, se desencadenó en 1970, y alcanzó la máxima intensidad durante los años 1973 a 1976. La derrota militar del agresor pudo apreciarse en 1978; digo derrota militar porque la guerrilla fue aniquilada, pero no vencida políticamente la subversión" (DÍAZ BESSONE, 1986: 11).

${ }^{12}$ Esta filiación no nacería en los años '60, sino que "cabe citar a los Partidos Comunistas de cada país (incluido el de Argentina) como instrumentos de la política internacional soviética. Su coordinación se opera particularmente desde la III Internacional (marzo de 1919) denominada Komintern por Lenin que la convocó cuando terminó la I Guerra Mundial. Fue completada por la Internacional Sindical Roja (1921). La III Internacional propone la revolución comunista mundial con el sostén de la URSS. Durante la Segunda Guerra Mundial, Stalin suprimió el Komintern (15 de mayo de 1943) a fin de eliminar problemas con los aliados, transitoriamente. Terminada la guerra, se fundó, se fundó el Kominform (septiembre de 1947) y funcionó en Belgrado hasta 1948, año en el que Tito fue excluido y la sede pasó a Rumania. Por su parte, Trotsky fundó la IV Internacional (1938), casi diez años después de haber sido expulsado de la URSS. Esta organización alcanzó gran importancia en América Latina. Adhirieron a ésta corriente varias organizaciones y partidos poco numerosos pero muy activos en la Argentina, como el Partido Socialista de los Trabajadores, el Partido Obrero, el Partido Obrero Trotskista (ex-Partido Obrero Revolucionario)" Ídem, (DÍAZ BESSONE, 1986: 58-59).
} 
colectiva, primero en la propia Rusia y luego en todo el mundo colonial y semi colonial, empezando por China, por lo que los revolucionarios burgueses del siglo XX adoptan el vocabulario y los símbolos [...] de la tradición socialista. Su fuente de inspiración no era sin embargo la sociedad prometida por la revolución bolchevique de 1917, sino la de la contrarrevolución estaliniana de 1928 [que] se manifestaba pretendiendo representar la sociedad que iba a suceder al capitalismo. [...] fuera de Rusia, el estalinismo se proponía establecer sociedades basadas en el capitalismo de Estado y consiguió hacerlo, aun pretendiendo [...] que se había iniciado la construcción del socialismo. Esos revolucionarios burgueses modernos no estaban necesariamente organizados en partido comunistas formalmente dependientes de la URSS (DAVIDSON, 2013: 876).

Davidson afirma que, en los países atrasados, debido a la debilidad de las burguesías locales, a su vinculación con sus pares de las potencias coloniales y a su temor a la participación de las masas en el proceso de independencia, la dirección revolucionaria fue asumida por miembros de la intelligensia, es decir, por intelectuales que, en sus palabras, constituyen una "burguesía no capitalista" que, en general, trata con desprecio a la burguesía realmente existente y prefiere al Estado como "alternativa modernizadora" (DAVIDSON, 2013: 877). ${ }^{13}$

Una idea similar aparece en el voluminoso estudio de David Priestland sobre la tradición comunista, en donde sostiene que "el Che se convirtió en una figura paradigmática y durante un tiempo Cuba fue uno de los modelos más atractivos para los nacionalistas radicales" (PRIESTLAND, 2010: 367). Respecto del caso africano, sostuvo que la teoría marxista atrajo a los llamados mestizos y asimilados, es decir, a los africanos e indios educados en Portugal como personal administrativo para las colonias, debido a que otorgaba preeminencia a la clase por encima de la raza, estableciendo una relación entre los intereses nacionalistas y los proyectos de desarrollo económico de los "partidos modernizadores" (PRIESTLAND, 2010). ${ }^{14}$

\footnotetext{
${ }^{13}$ Sin duda es debatible esta conceptualización, en tal sentido cabe preguntarse quienes son estos sujetos y acaso si es posible la existencia de una burguesía no capitalista.

14 Como el Movimiento Popular de Liberación de Angola (MPLA), el Partido Africano para la Independencia de Guinea y Cabo Verde (PAIGC) y el Frente de Liberación de Mozambique (FRELIMO). En sus palabras, "Al principio, los principales intereses de los nacionalistas eran sobre todo culturales: 'desportugalizar' y 'reafricanizar' la cultura angoleña; pero al mismo tiempo eran modernizadores muy conscientes que trataba de crear grandes estados al estilo europeo a partir de numerosos grupos tribales, por lo que no cabe sorprenderse de que adoptaran un marxismo modernista influido por la Unión Soviética, especialmente cuando una de las pocas fuerzas que se opusieron a Salazar en la metrópoli fue
} 


\section{El estudio de la Tricontinental y la OLAS}

Planteada la importancia de la Tricontinental y la OLAS por la historiografía, pronto comenzaron a realizarse los primeros estudios dedicados específicamente a ellas, aunque la mayor cantidad de investigaciones se concentra entre la última década del siglo pasado y, sobre todo, en las dos primeras del XXI.

La conferencia tuvo una rápida repercusión en el mundo académico, entrecruzado ya, a mediados de la década de 1960, con el activismo de izquierda. Las publicaciones de los principales partidos de izquierda a nivel mundial, de las más diversas corrientes (comunistas, trotskistas, maoístas y nacionalistas) reseñaron su realización (VARELA, 1966). ${ }^{15}$ Los primeros artículos y estudios monográficos fueron publicados el mismo año de la conferencia Tricontinental, en La Habana y en París, los se encuentran más cerca de la crónica documental que de la investigación, en tanto fueron realizados por autores que participaron de ella. Por un lado, el jurista Fernando Álvarez Tabío, director del Instituto de Política Internacional del Ministerio de Relaciones Exteriores cubano y decano de la Escuela de Ciencias Políticas de la Universidad de La Habana, dedicó un número especial de la revista de su instituto a la conferencia, el que incluía una breve descripción del evento y los principales documentos, publicada en marzo de 1966 (ALVAREZ TABÍO, 1966). Por su parte, la monografía del periodista francés Albert Léntine, invitado por el gobierno cubano a la Tricontinental, constituye la primera descripción sistemática de los debates desarrollados durante las dos primeras semanas de enero de 1966 en La Habana, presentado a un público europeo que, en sus palabras, no parecía impactado políticamente por el evento, en particular, y por la realidad del Tercer Mundo, en general (LÉNTIN, 1966). ${ }^{16}$ Poco después, cuando en América Latina comenzaba a ser evidente la influencia cubana, que Robert Lamberg intentó dilucidar la especificad de la

el Partido Comunista clandestino, que creó un partido hermano angoleño en 1954 [...] muchos nacionalistas modernizadores entraron en su órbita" (PRIESTLAND, 2010: 390).

${ }^{15}$ Estos textos deben considerarse, antes que como parte de la historiografía, como fuentes para el estudio del propio proceso.

16 "Invitado por el gobierno cubano, seguí el trabajo y estoy seguro de que asistí a un evento de gran importancia, a pesar de que causó poca respuesta en Europa. La dificultad de las comunicaciones con Cuba, que impide la información rápida y el gran desinterés que las sociedades occidentales tienen en general en los problemas del Tercer Mundo, explican esta situación. Aquellos que, sin embargo, ven las cosas desde arriba, están de acuerdo en que la reunión del Tricontinental 'será un hito en la historia del siglo XX." (Traducción propia) (LÉNTIN, 1966: 14). 
"línea castrista" a partir de un análisis del programa de la conferencia (LAMBERG, 1968: 378-301; DEBRAY, 1967 [1965]; HALPERIN, 1963; DRAPER, 1965; RATLIFF, 1986). También, fue presentada una síntesis sobre las organizaciones globales revolucionarias, entre las que destaca a la Tricontinental como una de las mejores organizadas y que presentaba "reglas universales específicas para la revolución", y a la OLAS, de la que aseguraba que su base en La Habana le otorgaba una ventaja por sobre los intentos maoístas y trotskistas de organización internacional (BOWYER BELL, 1971: 503-518). Por su parte, Pellicer de Brody publicó un ensayo en torno al antagonismo entre las estrategias emanadas de Moscú y La Habana. (PELLICER DE BRODY, 1972: 297-307).

Sorpresivamente, entre las décadas de 1970 y 1990 no hemos encontrado estudios monográficos que ahonden en el tema. El primer estudio dedicado a un aspecto parcial de la Tricontinental es una tesis de la Universidad de Londres, que no ha sido publicada, en la que Frances Wright estudió a la conferencia de La Habana como parte de la política internacional del gobierno de Cuba, particularmente, como un esfuerzo diplomático por transformar el eje de los enfrentamientos globales, en el sentido de que las batallas entre oriente y occidente cambien hacia una confrontación Norte-Sur, tratando, al mismo tiempo, de imponer a Fidel Castro como líder de la coalición Sur (WRIGHT, 1995). Su trabajo se coloca en una historiografía dedicada a la política exterior cubana, que vio en la Tricontinental un fin estrictamente defensivo, es decir, una respuesta a la ofensiva contrarrevolucionaria liderada por Estados Unidos para intentar controlar económica y militarmente el continente (ya sea mediante la implementación de la Alianza para el Progreso o de la invasión a República Dominicana, en 1965). De allí que el apoyo cubano, a través de un organismo internacional al despliegue de organizaciones político militares en el resto de países de Latinoamérica, permitiría desviar la atención norteamericana hacia dichos conflictos, y mitigar la presión que ejercía sobre la isla. (DOMINGUEZ, 1989; RODRIGUEZ OSTRIA, 2011: 216; ALLENDE KARAM, 2019).

También a fines de la década de 1990, a propósito del trigésimo aniversario de la Tricontinental, apareció un breve texto en La Habana, que presentó una síntesis del desarrollo de la conferencia y sus asistentes (CAPOTE, 1996). Nuevos aniversarios de la conferencia fueron celebrados en Cuba con artículos similares (REGALADO, 2011).

En la primera década del siglo XXI, fueron compilados algunos de los principales textos de la revista Tricontinental, editados por Ulises Estrada y Luis 
Suárez, en la que el primero incluye un breve relato de los primeros pasos de la publicación, que vio la luz en abril de 1966 (ESTRADA y SUÁREZ, 2006). Es muy valiosa su descripción sobre la redacción y publicación de "Crear dos, tres, muchos Vietnam": fue el primer secretario general de la OSPAAAL, Osmany Cienfuegos Gorriarán, quien le solicitó al Che Guevara, mientras éste se preparaba clandestinamente en el occidente cubano, que escribiera un artículo "destinado a ser el núcleo del primer número de la revista Tricontinental”, cuyo manuscrito dejó en sus manos antes de salir de Cuba, a fines de 1966 (ESTRADA y SUÁREZ, 2006: 2). ${ }^{17}$ Por su parte, Suárez presenta una breve historia de la OSPAAAL, fundada en enero de 1966, una ONG cuyos objetivos eran "adoptar 'las medidas prácticas dirigidas esencialmente a coordinar, apoyar e impulsar la solidaridad activa y revolucionaria' entre los partidos, organizaciones y movimientos populares, democráticos, revolucionarios, antiimperialistas y anticolonialistas de los 82 países del mundo inicialmente integrantes de la OSPAAAL" (ESTRADA y SÚAREZ, 2006: 5; SEIDMAN, 2012).

Posteriormente, la tesis que Lucia Moro realizó en la Universidad de Padova, que tampoco ha sido editada, continuó bajo el mismo tópico, dedicándose a la revista Tricontinental, principal órgano de difusión teórica. Preguntándose si la publicación se alineaba directamente con la política exterior de Cuba, caracteriza a la política cubana como una "vanguardia revolucionaria mundial, [que] lideró en ese momento una política exterior y parecía querer incluso crear una 'tercera vía' en el mundo socialista, luego atravesada por los contrastes chino-soviético, con el apoyo de Corea del Norte y Vietnam" (traducción propia del italiano) (MORO, 2011: 1).

De este punto de vista, hasta finales de la década del '60, Cuba habría impulsado "la revolución en el Tercer Mundo", desplegando una política exterior independiente de la soviética hasta que, a comienzos de 1970, su alineación con ésta última se profundizaría frenando aquel impulso. Según su periodización, Cuba volvería a radicalizar su política hacia 1980, cuando aumenta su apoyo a las luchas en Centroamérica para enfrentar la intervención norteamericana. Como se observa, este enfoque asocia la defensa de una estrategia armada y de los grupos u organizaciones

\footnotetext{
${ }^{17}$ Según su relato, se esperó a que el Che estuviera en condiciones de iniciar su lucha en América del Sur, antes de publicar su famoso llamamiento en un suplemento especial de la revista, el 16 de abril de 1967, el que pasó a la historia como "Mensaje a todos los pueblos del mundo a través de la Tricontinental". Por el contrario, Michel Lowy asegura que el texto fue escrito en la selva boliviana, en 1967 (LOWY, 2007: 303)
} 
guerrilleras que la llevan adelante, con la definición revolucionaria de dichas organizaciones y de la política cubana.

Siguiendo una tradición de estudios culturales dedicados a ponderar el papel de los proyectos intelectuales en los procesos revolucionarios latinoamericanos (ALBURQUERQUE, 2010: 95-116), Reinaldo Morales Campos recordó el legado artístico y cultural de la Tricontinental, considerándola un “espacio político mediático cuya labor comunicacional se centra en boletines, revistas, carteles, producciones literarias" (MORALES CAMPOS, 2011; 2012; HANNA, 2020; ROSENBLUM, 2005; PEZ FERRO, 1997).

En este sentido, se estudió la producción artística e intelectual emanada de la conferencia (fotografía, carteles, folletos, el Boletín y la Revista Tricontinental), y se la definió como un aparato de contra propaganda que enfrentó la desinformación emanada del mundo capitalista (YOUNG, 2018: 521-523).

Más recientemente, Saîd Bouamama publicó un breve ensayo que busca apropiarse de la tradición militante y antiimperialista de la Tricontinental (BOUAMAMA, 2016). Desde su perspectiva, un presente en el cual los pueblos sufren las consecuencias de la derrota en las guerras por los recursos naturales contra las grandes potencias capitalistas, impone la necesidad de comprender estos enfrentamientos en términos históricos, con el objetivo de reconstruir una ideología de resistencia internacionalista, que contribuya a reunificar las luchas a escala global. La asimilación de la compleja y contradictoria historia de la Tricontinental, como espacio de discusión de tácticas y estrategias de los oprimidos, serviría, entonces, para enfrentar a las ideologías del fin de la historia o del choque de civilizaciones.

Bouamama se concentra en la organización internacional de los pueblos oprimidos, fundamentalmente de Asia y África que ya conformaban, antes de la Tricontinental, la Organización para la Solidaridad de los Pueblos de Asia y África (OSPAA). A partir de ella, filia ideológicamente a la Conferencia Tricontinental con los congresos antimperialistas de Bruselas (1927) y Bandung (1955), señalando, asimismo, el estrecho vínculo con la Revolución Rusa de 1917 y con los levantamientos anticoloniales ocurridos en las primeras décadas del siglo $\mathrm{XX} .{ }^{18}$ En este sentido, presenta algunas de las cuestiones políticas que atravesaron a la conferencia, como los

\footnotetext{
${ }^{18} \mathrm{El}$ autor establece una vinculación orgánica entre los levantamientos obreros y anticoloniales de fines de la década de 1920 en Asia (China, Indonesia, Java, el gran levantamiento árabe en la región de Siria), en América (Sandino en Nicaragua) y en África (Guerra de Rif, en Marruecos) y la organización de los países oprimidos en la conferencia de Bruselas.
} 
límites de las alianzas nacionales y frentes policlasistas para alcanzar la liberación nacional e impulsar el desarrollo económico; o el protagonismo de la dirigencia africana en la organización de la conferencia, en particular del líder marroquí Ben Barka, también abordada por otros autores (AA.VV., 1967; BEN BARKA, 2007; GALLISSOT y KERGOAT, 1997). En síntesis, el trabajo de Bouamama, es un ensayo breve que aporta información significativa del proceso en cuanto a su filiación política, aunque privilegiando la intervención afroasiática, sin profundizar en la descripción del desarrollo de la conferencia ni en la intervención de las organizaciones latinoamericanas.

Sin lugar a dudas, el mejor libro sobre la Tricontinental fue escrito por el periodista francés Roger Faligot, que constituye el más pormenorizado análisis histórico a partir de fuentes primarias (documentos de la conferencia y de los servicios secretos, entrevistas a los protagonistas y artículos de la prensa internacional) y secundarias, que nos permiten adentrarnos tanto en su carácter global como en su papel en los debates políticos al interior del movimiento revolucionario (FALIGOT, 2013). Mostrando lo mejor de su profesión, Faligot presenta una brillante y pormenorizada reconstrucción cronológica de los hechos. De esta manera, prueba la vinculación entre las luchas de Asia, África y América Latina, de la cual la conferencia Tricontinental es expresión orgánica, a través de la reconstitución minuciosa de la red de dirigentes construida principalmente por Ben Barka. El estudio de Faligot muestra que esta red reunió a líderes de Estado y a jefes de organizaciones político militares clandestinas, vinculándose, incluso, con dirigentes trotskistas, como Michael Pablo, uno de los máximos referente de la IV Internacional, y que tuvo en el Che Guevara a uno de sus principales organizadores, como ejecutor material de la política emanada directamente del gobierno cubano. Su hipótesis plantea, entonces, que la Tricontinental se constituyó en el órgano coordinador de luchas que ya estaban en marcha.

No obstante, al igual que sus predecesores, el estudio se concentra en el papel jugado por África en la organización y desarrollo de la conferencia, relegando la intervención latinoamericana. Por otro lado, aunque menciona la intervención de Pablo, no profundiza en la relación entre el trotskismo y la Tricontinental.

Sobre la influencia de la Tricontinental en América latina, Juan Alberto Bozza presentó recientemente una ponencia basada en documentación cubana y en los documentos desclasificados de la Agencia Central de Inteligencia (CIA), concluyendo que la conferencia constituyó una "cantera de experiencias en las que movimientos de 
liberación nacional podían devenir en agentes de la revolución socialista" (BOZZA, 2018; 2014; HARRIS, 2009: 27-42; TRETO, 2010: 161-185; HERNÁBDEZ, 2013: 177-198; HARMER, 2013: 61-89; HATZKY \& STITES MOR, 2014: 127-140)

Respecto del estudio de la OLAS, es llamativa la inexistencia de un trabajo dedicado exclusivamente a su análisis, sobre todo, como veremos, debido al protagonismo que tuvo en la política latinoamericana. Los primeros análisis constituyen, como en el caso de la Tricontinental, fuentes, antes que estudios historiográficos, en tanto fueron escritos por intelectuales militantes al calor de los eventos (METHOL FERRÉ, 1967: 17 y ss.; GUTIÉRREZ, 1967a: 1967b: 21; AMIGÓ, 1967: 523-531).

A poco de finalizar la OLAS, un ensayo de Clodomiro Almeyda la caracterizó, junto a la Tricontinental, como expresión de un "internacionalismo revolucionario", promovido frente al quietismo resultante de la aceptación de la política de coexistencia pacífica por parte de los partidos comunistas que adherían a las directrices soviéticas (ALMEYDA, 1967). La primera monografía breve de la que tenemos noticias fue publicada en 1968 en Montevideo por Ariel Collazo, que asistió al evento y enfrentó la política de Fidel Castro y el Partido Comunista de Uruguay, representada por Rodney Arismendi (COLLAZO, 1968).

Al igual que en el caso de la Tricontinental, entre las décadas de 1980 y 1990 no encontramos estudios que hayan ahondado sobre la cuestión. Ya en el siglo XXI, escasos, pero valiosos estudios, comenzaron a atender a aspectos específicos. Por un lado, Eduardo Rey Tristán y Mariana Villaça analizaron el caso uruguayo, presentando una primera mirada sobre el debate en torno a la estrategia de la revolución latinoamericana, y sobre la OLAS a través del periódico Marcha (REY TRISTÁN, 2005: 1693-1706; VILLAÇA, 2017: 309-336). Por su parte, Patricia Calvo ha ofrecido una mirada más de conjunto, por medio del análisis del Boletín de Información del comité organizador de la OLAS, publicado entre 1966 y 1967 (CALVO, 2018: 155$185)$.

En síntesis, mientras que los estudios sobre la Tricontinental no sólo son escasos, sino que se enfocan, principalmente, en su impacto en Asia y África, relegando el papel de América Latina, no existe ninguna monografía dedicada a la OLAS, y los pocos artículos sobre su historia abordan aspectos parciales, que concluyen en su enorme importancia que ella tuvo en la historia de la izquierda latinoamericana, señalando la necesidad de avanzar en su estudio a partir de casos históricos específicos. 


\section{El impacto de la OLAS en la izquierda de la Argentina}

En la Argentina, existe una nutrida bibliografía sobre las organizaciones político-militares, dedicada a una importante diversidad de temas y problemas (OIKÓN SOLANO, REY TRISTÁN, LÓPEZ, 2014). No obstante, como ya hemos señalado, no existen estudios específicos sobre el impacto de la Tricontinental y la OLAS, o de la participación de los partidos y organizaciones del país en su constitución y desarrollo.

De todas maneras, esto no significa que el tema no haya sido tratado y que no existan antecedentes. Las historias de las corrientes, partidos y organizaciones de la izquierda, así como los estudios sobre la lucha de clases y la guerra revolucionaria en las décadas de 1960 y 1970, muestran la importancia que tuvieron estos eventos internacionales impulsados desde La Habana.

De las fuerzas políticas que participaron de la Tricontinental y la OLAS de la Argentina, la que más atención recibieron fueron el comunismo y el peronismo. Las zigzagueantes posiciones del Partido Comunista de la Argentina frente al proceso cubano fueron registradas tanto en libros de divulgación como en artículos científicos, aunque no existe un balance general sobre la cuestión (MASSHOLDER, 2018: 122136; LIBERMAN, 2017: 49-58; ARTARAZ, 2011). Respecto del sector peronista vinculado al proceso cubano, se han publicado las obras escogidas de quien fuera el presidente de la delegación argentina en la Tricontinental y la OLAS, John William Cooke (quien formaba parte de Acción Revolucionaria Peronista) y también existen estudios sobre su trayectoria política (DUHALDE, 2007; 2009; 2010; 2011).

Asimismo, se ha señalado la participación, tanto en la reunión preparatoria como en la conferencia Tricontinental y en la OLAS, del Movimiento de Liberación Nacional (MLN), destacándose la diferencia estratégico militar planteada por dicha organización, en tanto defendían una salida insurreccional, en oposición a una estrategia foquista (PACHECO, 2010; 2012).

Por su parte, también se han investigado un conjunto de pequeñas organizaciones armadas que se encontraban activas durante la segunda mitad de la década de 1960, y que se vincularon de hecho a la lucha armada, particularmente la Brigada Masetti (proveniente del Ejército Guerrillero del Pueblo, derrotado en Salta, en 1964; luego integrante de las Fuerzas Armadas de Liberación -FAL-) y las Fuerzas 
Armadas Revolucionarias (que habían roto con el PCA por la oposición rotunda de éste a seguir la denominada "vía armada hacia el socialismo" (GRENAT, 2010; CAVIASCA, 2006b: 82-97; GONZALEZ CANOSA, 2015: 56-83).

Finalmente, una de las corrientes que más atención ha recibido fue el trotskismo, la que presentó el poderoso impacto de la Tricontinental y la OLAS en la corriente fundada por León Trotsky. Los primeros estudios del historiador norteamericano Robert Alexander han señalado el carácter contradictorio del vínculo entre el gobierno cubano y el trotskismo: aunque Fidel atacó en su discurso de cierre de la Tricontinental a la tendencia posadista (particularmente a Yon Sosa, dirigente del Movimiento Revolucionario 13 de Noviembre, de Guatemala M-13), mantuvo un vínculo con el Secretariado Unificado (ALEXANDER, 1991, ACOSTA DE ARRIBA, 2017).

Posteriormente, también Osvaldo Coggiola, historiador y militante del Partido Obrero de la Argentina (en las décadas de 1960 y 1970, Política Obrera), se refirió a la Tricontinental en el marco del ataque de Castro a los trotskistas, a los que acusó de "contrarrevolucionarios al servicio del imperialismo (COGGIOLA, 2006: 439). Asimismo, menciona el impacto diferenciado de la OLAS en las dos principales organizaciones que se disputaban la dirección de la IV Internacional, el Secretariado Unificado (SU) (con Pierre Frank, Ernest Mandel y Joseph Hansen a la cabeza, que adhirió a la lucha armada), y la Organización Comunista Internacional (OCI) (que, dirigida por Pierre Lambert, enfrentó dicha estrategia) (HENTZGEN, 2019).

Finalmente, Coggiola asegura que este proceso impactó con fuerza en las agrupaciones trotskistas latinoamericanas (como el MIR chileno, el POR boliviano, el PRT y PO en Argentina), produciendo escisiones y fraccionamientos al calor del debate en torno a la estrategia armada y a las formas de organización de la fuerza social revolucionaria. ${ }^{19}$

Posteriormente, Ernesto González, historiador y militante de la corriente dirigida por Nahuel Moreno, realizó una voluminosa y documentada historia del trotskismo en la Argentina, en la que presentó un balance de la intervención de Palabra Obrera en tres grandes procesos de la etapa, vinculados a la cuestión de la lucha armada: la toma de tierras en Perú, dirigida por Hugo Blanco (1962); el envío de militantes a entrenarse

\footnotetext{
${ }^{19}$ Quien desarrolla esta tesis es Michel Lowy, asegurando que el PRT de la Argentina expresaba una "alianza trotskista-guevarista" que "cristalizó en el IX Congreso de la IV Internacional (1969), que proclamó una orientación a favor de la lucha armada y de la integración de las organizaciones trotskistas en la corriente OLAS. Durante la década de 1970, sin embargo, divergencias estratégicas y tácticas llevaron a un alejamiento de las dos tendencias, que, a pesar de eso, mantuvieron relaciones fraternales en la mayoría de los países" (LOWY, 2007: 53).
} 
militarmente a Cuba -entre ellos, un miembro de la dirección partidaria, Ángel "el Vasco" Bengoechea (NICANOFF y CASTELLANO, 2006); y, finalmente, el impacto provocado por la OLAS en el Partido Revolucionario del Pueblo (PRT), que se había fundado el 25 de mayo de 1965, como resultado de la unificación de Palabra Obrera con el Frente Revolucionario Indoamericano Popular (FRIP), liderado por Mario Roberto Santucho (GONZÁLEZ, 1999). ${ }^{20}$

El estudio asegura que el PRT adhirió a la convocatoria del Comité Organizador de la OLAS, y brindó todo su apoyo al organismo por considerar que rompía abiertamente "con los partidos stalinistas", asegurando que la OLAS se constituiría en una nueva dirección revolucionaria a escala continental y analizando particularmente la historia del vínculo entre el PRT y el SU de la IV Internacional (GONZÁLEZ, 1999: 189). Sin embargo, asegura que "el impacto de estos hechos produjo fuertes presiones sobre sus filas, iniciándose un proceso de grave crisis interna. Mientras una parte del partido intentaba mantener su estructuración en la clase obrera, muchos militantes, desilusionados de la lucha de masas, empezaron a buscar un 'atajo' impulsando la acción guerrillera" (GONZÁLEZ, 1999: 185) El resultado final de esta crisis fue la división del partido en el PRT- La Verdad (dirigido por Moreno) y el PRT-El Combatiente (de Santucho) (MANGIANTINI, 2014), lo que condujo a González a presentar un balance negativo de la Tricontinental y la OLAS, en tanto habrían producido un impacto negativo en el proceso revolucionario debido a que "durante todo 1967 la orientación del partido se vio casi completamente atravesada por la estrategia de este organismo que, como veremos, era equivocada". En este sentido, considera que la dirección ejercida por Cuba habría impedido:

la unificación y organización del vasto movimiento al que había dado origen. Las relaciones con las organizaciones y grupos que se reivindicaban castristas fueron encaradas bilateralmente, sin intentar nuclearias en una organización unitaria. Incluso la creación de la Organización Latinoamericana de Solidaridad (OLAS) en 1966, no superó esa estructura laxa, como veremos más adelante. Si bien Castro y especialmente el Che insistían en el carácter continental de la lucha antiimperialista, su práctica

\footnotetext{
${ }^{20}$ Según González, a su regreso a la Argentina, Bengoechea "generó un debate acerca de la teoría de la revolución elaborada por el Che -conocida como 'foquismo"” que concluyó con su separación del partido y su incorporación al proyecto del Che Guevara (GONZÁLEZ, 1999: 8).
} 
con respecto a las organizaciones siguió siendo nacionalista (GONZÁLEZ, 1999: 31$)^{21}$

Luego de la publicación del trabajo pionero de Coggiola se realizaron pocos intentos por aprehender la historia del trotskismo a escala latinoamericana y la mayoría de los estudios se dedicó, o bien a casos nacionales o a organizaciones específicas (PALIERAKI, 2014; VERGARA ÁLVAREZ, 2015; JOHN, 2016). ${ }^{22}$ En el caso de la Argentina, la historiografía privilegió el estudio del PRT-ERP y la corriente morenista (MATTINI, 2003, SANTUCHO, 2004; WEIS, 2004; 2006a; 2006b; DE SANTIS, 2011; CARNOVALE, 2010; 2011; POZZI, 2001). Esto alcanza a los estudios que comenzaron a realizar un balance del impacto de la Revolución cubana y la lucha armada en las organizaciones trotskistas latinoamericanas y de la Argentina (MEUCCI, 2015; MANGIANTINI, 2015; CHILCOTE, 2009: 719-741). Se encuentra pendiente, entonces, dilucidar el papel jugado en el proceso por organizaciones como Política Obrera, que presenta pocas investigaciones (más allá de Coggiola), y Baluarte, de la que no hemos encontrado ningún estudio pese a que participó de la OLAS.

\section{Conclusiones}

La historiografía global, así como la dedicada al estudio del Tercer Mundo, América Latina y la historia del socialismo han señalado, inequívocamente, la importancia de la conferencia Tricontinental de La Habana y de la OLAS, aunque su papel en la historia del siglo XX aún no encuentra una interpretación definitiva.

$\mathrm{Su}$ intento por constituirse en dirección estratégica de los pueblos oprimidos coloca a ambos eventos como observables privilegiados para el estudio de los procesos conscientes, es decir, político-intelectuales, por direccionar el proceso revolucionario global de las décadas de 1960 y 1970.

No obstante, mientras que los estudios dedicados a la conferencia de La Habana son escasos, también se han enfocado, principalmente en el papel jugado por Asia y África, relegando el impacto de ambos eventos en la política latinoamericana.

\footnotetext{
${ }^{21}$ Hemos analizado el debate entre trotskismo y foquismo en (GRENAT, 2011a).

${ }^{22}$ John asegura que el POR boliviano participó del Consejo Democrático del Pueblo (CODEP), que envió una delegación a la Tricontinental, aunque no fue admitida, bajo el argumento que el único representante oficial era el Partido Comunista de Bolivia (JOHN, 2016: 257).
} 
Por su parte, los análisis sobre la organización específicamente creada para la coordinación de las luchas en América latina, la OLAS, no sólo es incipiente en términos generales, sino que también presenta avances limitados a escala nacional: la cuestión sobrevuela una enorme producción dedicada a las organizaciones políticomilitares, pero aún aguarda por una investigación que describa y explique su papel en la historia política de América latina y el mundo.

El estudio de caso de la Argentina muestra que, aunque se avanzó en el análisis de una parte de las organizaciones que participaron de la Tricontinental y la OLAS, aún se encuentra pendiente un mejor conocimiento de un conjunto de partidos que, o bien desde la crítica, o bien sumándose al proceso impulsado desde La Habana, participaron de la lucha política en las décadas de 1960 y 1970.

\section{Referências bibliográficas}

AA.VV. (1967). El pensamiento político de Ben Barka. La Habana: Ediciones Tricontinental;

ACOSTA DE ARRIBA, Rafael (2017). El final del trotskismo organizado en Cuba. En: MASSÓN, Caridad (Ed.). Las izquierdas latinoamericanas. Multiplicidad y experiencias durante el siglo XX. Santiago de Chile: Ariadna.

ALBURQUERQUE, G. (2010). Los intelectuales latinoamericanos y la construcción cultural del tercer mundo: concepto, imagen, ideología (1952-1991). En: História Social, vol. 1, No 18, pp. 95-116.

ALBURQUERQUE, Germán (2017). Cuba en el Movimiento de Países no Alineados: el camino al liderazgo. En: Caravelle, $\mathrm{N}^{\circ} 109$, pp. 173-193.

ALEXANDER, Robert (1991). International Trotskyism. 1929-1985. A documented analysis of the movement. Duke: University Press.

ALLENDE KARAM, Isabel (2019). Una mirada sobre la política exterior de la Revolución Cubana y las dimensiones de su universalidad. En: SUÁREZ SALAZAR, Luis (Coord.) Cuba en revolución. Miradas en torno a su sesenta aniversario. Buenos Aires: CLACSO.

ALMEYDA, Clodomiro (1967). La OLAS y la crisis política en América Latina. En: Estudios Internacionales, vol. 1, N 3/4, 1967, pp. 427-442.

ÁLVAREZ TABÍO, Fernando (1966). Primera Conferencia de Solidaridad de los Pueblos de Asia, África y América Latina”. En: Política Internacional, n ${ }^{\circ}$ 13, La Habana, Instituto de Política Internacional, primer semestre.

AMIGÓ, Gustavo (1967). De la Sierra Maestra a los Andes Bolivianos, por la Organización Latinoamericana de Solidaridad: O.L.A.S. Revista Javierana, $\mathrm{N}^{\mathrm{o}}$ 340, T. LXVIII, nov.-dic. de 1967, pp. 523-531.

ANGELL, Alan (1997). La izquierda en América Latina desde c. 1920. En: BETHELL, Leslie, ed. Historia de América Latina, tomo 12. Política y sociedad desde 1930. Barcelona: Cambridge University Press-Crítica, pp. 73-129. 
ANSALDI, Waldo y GIORDANO, Verónica (2012). América Latina. La construcción del orden, tomo II. Buenos Aires: Ariel.

ARTARAZ, Kepa (2011). Cuba y la nueva izquierda. Buenos Aires: Capital Intelectual.

BARCIA, M. (2009). Locking horns with the Northern Empire: anti-American imperialism at the Tricontinental Conference of 1966 in Havana. Journal of Transatlantic Studies, 7(3), pp. 208-217.

BEN BARKA, Bachir (coord.) (2007). Mehdi Ben Barka en héritage. De la Tricontinentale à l'altermondialisme. Paris, Tarik, Casablanca: Syllepse.

BERMÚDEZ ERAZO, V. D. R. (2014). Política exterior y cooperación sur-sur: una discusión a la luz de la experiencia cubana. Tesis de Maestría, FLACSO-Ecuador.

BOUAMAMA, Saîd (2016). La Tricontinental, les peuples du tiers-monde à l'assaut du ciel. Paris: Editions du Cetim.

BOWYER BELL, J. (1971). Contemporary Revolutionary Organizations. International Organization, $\mathrm{N}^{\circ} 25$, pp. 503-518.

BOZZA, Alberto (2014). La resignificación de la conferencia OLAS en la nueva izquierda como sureña [1967]. En: TORTTI, María Cristina; CHAMA, Mauricio; CELENTANO, Adrián, dir. La nueva izquierda argentina [1955-1976]: Socialismo, peronismo y revolución. Rosario: Prohistoria.

BOZZA, Juan Alberto (2018). Tricontinental: Perspectivas y debates en la nueva izquierda latinoamericana e internacional. En: Actas de las X Jornadas de Sociología de la UNLP, Ensenada: Universidad Nacional de La Plata, FaHCE, Departamento de Sociología www.memoria.fahce.unlp.edu.ar/trab_eventos/ev.11391/ev.11391.pdf Acceso en: 26 may.2020.

CALVO, Patricia (2018). La Organización Latinoamericana de Solidaridad (OLAS) a través del Boletín de Información de su Comité Organizador (1966-1967). Revista de Historia Social y de las Mentalidades, vol. 22, n 1, pp. 155-185.

CAPOTE, René Anillo (1996). La solidaridad tricontinental: mucho más que un anhelo. La Habana: Editora Política.

CARNOVALE, Vera (2010). El morenismo y la lucha armada en la etapa formativa del Partido Revolucionario de los Trabajadores (1963-1968). En: Actas de la VI Jornadas de Sociología de la UNLP. Facultad de Humanidades y Ciencias de la Educación de la Universidad Nacional de La Plata www.aacademica.org/000-027 Acceso en: 15 nov. 2019.

CASTAÑEDA, Jorge G. (1993). La utopía desarmada. Intrigas, dilemas y promesa de la izquierda en América Latina. Buenos Aires: Ariel.

CAVIASCA, Guillermo (2006a). Dos caminos. ERP-Montoneros en los setenta. Buenos Aires: Ediciones del CCC.

CAVIASCA, Guillermo (2006b). Arturo Lewinger y los orígenes de FAR". En: Lucha Armada en la argentina, $\mathrm{N}^{\circ}$ 6, mayo/junio/julio, pp. 82-97.

CHEN, Jian et al. (2018). The Routledge handbook of the global sixties: between protest and nation-building. New York: Routledge,

CHILCOTE, R. H. (2009). Trotsky and Development Theory in Latin America. Critical Sociology, 35(6), 719-741.

COGGIOLA, Osvaldo (2006). Historia del Trotskismo, en Argentina y América Latina, Ediciones ryr, Buenos Aires.

COLLAZO, Ariel (1968) La OLAS: el camino revolucionario de los trabajadores. Montevideo: LYS Editores.

DAVIDSON, Neil (2013). Transformar el mundo. Revoluciones burguesas y revolución social. Barcelona: Ediciones pasado y Presente. 
DE SANTIS, Daniel (2011). La historia del PRT-ERP por sus protagonistas. Buenos Aires: Editora Guevarista.

DEBRAY, Regis (1967[ $1^{\circ}$ ed. en inglés New Left Review, $\left.\left.N^{\circ} 33,1965\right]\right)$. El castrismo: la larga marcha de América Latina. Montevideo: Cuadernos de Marcha, $\mathrm{N}^{\circ} 3$. Montevideo.

DÍAZ BESSONE, Ramón Genaro (General de División) (1986). Guerra Revolucionaria en la Argentina (1959-1978). Buenos Aires: Círculo Militar.

DOMINGUEZ, Jorge I. (1989). To make a world safe for Revolution. Cuba`s foreign policy. Harvard: Harvard University.

DRAPER, Theodore (1965). Castroism: Theory and Practice. New York: Frederick A. Praeger.

DROZ, Jacques (Coord.) (1986). Historia general de socialismo. Desde 1945 a nuestros días, volumen 235. Barcelona: Destino Libro.

DUHALDE, Eduardo Luis (Com.) (2009). John William Cooke. Obras Completas. Artículos periodísticos, reportajes, cartas y documentos. Tomo III. Buenos Aires: Editorial Colihue,

DUHALDE, Eduardo Luis (Com.) (2010). John William Cooke. Obras Completas. Peronismo y revolución Artículos periodísticos, reportajes, cartas y documentos (1947-1949). Tomo IV. Buenos Aires: Editorial Colihue,

DUHALDE, Eduardo Luis (Com.) (2011). John William Cooke. Obras Completas. Peronismo y revolución Artículos periodísticos, reportajes, cartas y documentos. Tomo V. Buenos Aires: Editorial Colihue.

DUHALDE, Eduardo Luis (Comp.) (2007). John William Cooke. Obras Completas. Correspondencia Perón Cooke. Tomo II. Buenos Aires: Editorial Colihue.

ESCOBAR, Arturo (2007). La invención del Tercer Mundo. Construcción y deconstrucción del desarrollo. Caracas: Fundación editorial el perro y la rana.

ESTRADA, Ulises y SUÁREZ, Luis (Ed.) (2006). Rebelión Tricontinental. Las voces de los condenados de la tierra en África, Asia y América Latina. Melbourne-New York-La Habana: Ediciones Tricontinental - Ocean Press.

FALIGOT, Roger (2013). Tricontinentale. Quand Che Guevara, Ben Barka, Cabral, Castro et Hô Chi Minh préparaient la révolution mondiale (1964-1968). París: La Découverte.

FAULKNER, Neil (2013). De los neandertales a los neoliberales. Una historia marxista del mundo. Barcelona: Pasado y Presente.

FERRO, Marc (2000 [1994]) La colonización. Una historia global. México: Siglo XXI.

FONTANA, Josep (2017). El siglo de la revolución. Una historia del mundo desde 1914. Barcelona, Crítica.

FONTANA, Josep (2017). Por el bien del imperio: una historia del mundo desde 1945. Barcelona: Pasado y Presente.

GALLISSOT, René y KERGOAT, Jacques (Eds.) (1997). Mehdi Ben Barka. De l'indépendance marocaine à la Tricontinentale. Paris: Karthala Institut MaghrebEurope,

GASPAR, Gabriel (1997). Guerrillas en América Latina. Chile: FLACSO.

GILLY, Adolfo (1986). La senda de la guerrilla (por todos los caminos/2). México: Nueva Imagen.

GONZALEZ CANOSA, Mora (2015). Un sendero guevarista: pervivencias y torsiones en los orígenes de las "Fuerzas Armadas Revolucionarias" (1966-1970). En: Izquierdas, $\mathrm{N}^{\circ} 15$, Santiago de Chile, pp. 56-83. 
GONZÁLEZ, Ernesto (Coord.) (1999). El trotskismo obrero e internacionalista en la Argentina. Tomo 3: Palabra Obrera, el PRT y la Revolución Cubana Vol. 1(19591963) y Vol. 2 (1936-1969). Buenos Aires: Editorial Antídoto.

GONZALEZ, Mike (1984). The Culture of the Heroic Guerrilla: The Impact of Cuba in the Sixties. In: Bulletin of Latin American Research, vol. 3, No. 2, pp. 65-75.

GOTT, Richard (1971). Guerrilla Movements in Latin America. New York: Doubleday \& Company, Inc.

GRAMSCI, Antonio (2000 [1984]). Los intelectuales y la organización de la cultura. Buenos Aires: Nueva Visión.

GRAMSCI, Antonio (2001 [1984]). Notas sobre Maquiavelo sobre la política y sobre el Estado moderno. Buenos Aires: Nueva Vision.

GRENAT, Stella (2010). Una espada sin cabeza. Las FAL y la construcción del partido revolucionario en los '70. Buenos Aires, Ediciones ryr.

GRENAT, Stella (2011). Las armas de la revolución latinoamericana. Prólogo: LORA, Guillermo. Revolución y Foquismo. Balance de la discusión sobre la desviación "guerrillerista". Buenos Aires: Ediciones ryr.

GUILLÉN, Abraham (1969). Desafío al Pentágono. La guerrilla latinoamericana. Montevideo: Editorial Andes, Montevideo.

GUTIÉRREZ, Carlos (1967a). OLAS: dos líneas, una acción común. Marcha, Nº 1364, p. 19.

GUTIÉRREZ, Carlos (1967b). OLAS: nace una Internacional. Marcha, № 1365, p. 21.

HALPERÍN DONGHI, Tulio (2005 [1967]). Historia Contemporánea de América Latina, Madrid: Alianza. 19a ed. en español.

HALPERIN, Ernst (1963). The ideology of Castroism and its impact on the communist parties of Latin America. Cambridge: Center for International Studies, Massachusetts of Technology.

HANNA, Lani (2020). Tricontinental's International Solidarity. Emotion in OSPAAAL as Tactic to Catalyze Support of Revolution. Radical History Review, Issue 136, pp. 169-184.

HARMAN, Chris (2013). Historia mundial del pueblo. Desde la Edad de Piedra hasta el nuevo milenio. Madrid: Akal,

HARMER, T. (2013). Two, Three, Many Revolutions? Cuba and the Prospects for Revolutionary Change in Latin America, 1967-1975. Journal of Latin American Studies, Vol. 45, No 01, pp. 61-89.

HARNECKER, Marta (1999). Haciendo posible lo imposible: la izquierda en el umbral del siglo XXI. México: Siglo XXI.

HARRIS, Richard L. (2009). Cuban internationalism, Che Guevara, and the survival of Cuba's socialist regime. Latin American Perspectives, vol. 36, no 3, pp. 27-42.

HATZKY, C., \& STITES MOR, J. (2014) Latin American Transnational Solidarities: Contexts and Critical Research Paradigms. Journal of Iberian and Latin American Research, Vol. 20, № 2, pp. 127-140.

HENTZGEN, Jean (2019). Du trotskysme à la social-démocratie: le courant lambertiste en France jusqu'en 1963. Tesis (Doctorado en Historia), Normandie Université, Normandie.

HERNÁBDEZ, Juan Luis (2013). Cuba: el 'gran debate' de los '60. En: GUEVARA, Gustavo (Coord.), Sobre las revoluciones latinoamericanas del siglo XX. Buenos Aires: Newen Mapu, pp. 177-198.

HOBSBAWM, Eric (1998). Historia del siglo XX. Buenos Aires: Critica.

HOBSBAWM, Eric (2018). Viva la revolución. Sobre Latinoamérica. Barcelona: Planeta, Barcelona. 
JOHN, Sandors (2016). Revolución permanente en el Altiplano. El trotskismo boliviano. Bolivia; Editores Plural.

KAPCIA, Antoni (2012 [2008]). Cuba in revolution: a history since the fifties. London: Reaktion Books.

LAMBERG, Robert (1968). La formación de la línea castrista desde la Conferencia Tricontinental. Foro Internacional, vol. 8, No 3 (31), pp. 278-301.

LENIN, Vladimir (1960 [1902]). ¿Qué hacer? Obras Completas, tomo V. Buenos Aires: Editorial Cartago, pp. 351-533.

LÉNTIN, Albert Paul (1966). La lutte Tricontinentale. Impérialisme et révolution après la conférence de La Havane. París: François Maspero.

LIBERMAN, Tamara (2017). La influencia de la Revolución Cubana en la izquierda latinoamericana: Reflexiones para la construcción de nuevos caminos en el siglo XXI. En: MASSÓN, Caridad (Ed.). Las Izquierdas Latinoamericanas: Multiplicidad y Experiencias durante el Siglo XX. Santiago de Chile: Ariadna Ediciones, pp. 49-58.

LOWY, Michel (2007). El marxismo en América Latina. Santiago de Chile: LOM Ediciones.

MAHLER, Anne Garland (2015). The global south in the belly of the beast. Viewing African American Civil Rights through a Tricontinental Lens. Latin American Research Review, Vol. 50, N 1, pp. 95-116.

MAHLER, Anne Garland (2017). Beyond the Color Curtain: The Metonymic Color Politics of the Tricontinental and the (New) Global South. In: BYSTROM, Kerry and SLAUGHTER, Joseph R. (Ed.). The Global South Atlantic. New York: Fordham University Press, 2017, pp. 99-123.

MAHLER, Anne Garland (2018). From the Tricontinental to the Global South: Race, Radicalism, and Transnational Solidarity. Durham, NC: Duke University Press.

MANGIANTINI, Martín (2014). El Trotskismo y el debate en torno a la lucha armada. Moreno, Santucho y la ruptura del PRT. Buenos Aires: El Topo Blindado.

MANGIANTINI, Martin (2015). Entre tensiones y redefiniciones: el trotskismo argentino ante el paradigma de la Revolución Cubana. En: XI Jornadas de Sociología. Facultad de Ciencias Sociales, Universidad de Buenos Aires.

MANSILLA, H. C. F. (1987). Latin America within the Third World: The Search for a New Identity, the Acceptance of Old Content. Canadian Journal of Latin American and Caribbean Studies, vol. 12, No 24, pp. 87-101.

MARCHESI, Aldo (2017). The Subjective Bonds of Revolutionary Solidarity. From Havana to Nancahuazú (Bolivia), 1967. En: Latin America's Radical Left: Rebellion and Cold War in the Global 1960s. Cambridge: Cambridge University Press, pp. 23-68.

MARCHESI, Aldo (2019). Hacer la revolución. Guerrillas latinoamericanas de los 60 a la caída del muro. Buenos Aires: Siglo XXI.

MASSHOLDER, Alexia (2018). La recepción de la Revolución Cubana en los Partidos Comunistas de América Latina. Izquierdas, $N^{\circ}$ 42, pp. 122-136.

MATTINI, Luis (2003). Hombres y mujeres del PRT-ERP de Tucumán a la Tablada. La Plata: De la Campana.

METHOL FERRÉ, Alberto (1967). Bajo el signo de Debray y la OLAS. Revista Víspera, año $1, \mathrm{~N}^{\circ} 3$, pp. 17 y ss.

MEUCCI, Isabella Duarte Pinto (2015). A Revolução Cubana e o movimento trotskista na América Latina: impactos na construção de um projeto político (1959-1974). Tesis (Maestría en Ciencia Política). Universidade Estadual de Campinas. Sao Paulo. 
MORALES CAMPOS, Reinaldo (2011). A 45 años de la OSPAAAL: Arte y solidaridad Tricontinental", en América Latina en Movimiento Online, Agencia Latinoamericana de Información (ALAI), Quito, Ecuador, http://www.alainet.org/es/active/43517. Acceso: 22 may. 2020.

MORALES CAMPOS, Reinaldo (2012). 45 años haciendo historia, defendiendo cultura y expresando solidaridad. Tributo a la revista Tricontinental. En: América Latina en Movimiento Online, Agencia Latinoamericana de Información (ALAI), Quito, Ecuador https://www.alainet.org/es/active/53379). Acceso: 22 may. 2020.

MORO, Lucia (2011). La Tricontinental, una rivista per la rivoluzione. Corso di laurea Specialistica in Storia Moderna e Contemporanea, Università Degli Studi di Padova,

NICANOFF, Sergio y CASTELLANO, Axel (2006). Las primeras experiencias guerrilleras en la Argentina. La historia del Vasco Bengochea y las Fuerzas Armadas de la Revolución Nacional. Ediciones del CCC, Bs. As.

OBREGÓN, L. (2017). Latin America during the Bandung Era: Anti-Imperialist Movements vs. Anti-Communist States. In: L. ESLAVA, M. FAKHRI, \& V. Nesiah (Eds.). Bandung, Global History, and International Law: Critical Pasts and Pending Futures. Cambridge: Cambridge University Press, pp. 232-246.

OIKÓN SOLANO, Verónica; REY TRISTÁN, Eduardo; LÓPEZ ÁVALOS, Martín (Ed.) (2014). El estudio de las luchas revolucionarias en América latina (19591996). Estado de la cuestión. Santiago de Compostela: El Colegio de Michoacán Universidad de Santiago de Compostela.

PACHECO, Julieta (2010). El Movimiento de Liberación Nacional (MLN) y la discusión sobre la estrategia armada en la Argentina (1960-1969). Revista Izquierdas, vol. 3 , no 6.

PACHECO, Julieta (2012). Nacional y Popular. El MLN-MALENA y la construcción del programa de liberación nacional (1955-1969). Buenas Aires: Ediciones ryr,

PALIERAKI, Eugenia (2014). ¡La revolución ya viene ¡El MIR chileno en los años sesenta! Santiago de Chile: LOM Ediciones.

PELLICER DE BRODY, Olga (1972). Cuba y América Latina: ¿coexistencia pacífica o solidaridad revolucionaria? Foro Internacional, vol. XII, 3 (47), pp. 297-307.

PEREYRA, Daniel (2011). Del Moncada a Chiapas. Historia de la lucha armada en América Latina. Buenos Aires: Ediciones ryr.

PEZ FERRO, Ramón (1997). La OSPAAAL y sus ediciones Tricontinental. Tribunas de solidaridad, disponible en http://web.tiscali.it/ilpapiro/Spagnolo.htm. Acceso en: 12 dic. 2019.

PIEHL, Robert H. (1966) (Liutenent Colonel, United States Marine Corps). Cuban Subversion: Shadow over Latin America y KOLB, James T. (Colonel, Armor). Communist China's National Strategy in Latin America, ambas editadas por el US Army War College, Carlisle Barracks, Pennsylvannia, [Student Thesis].

PIÑEIRO, Manuel (2001). Che Guevara and the Latin American Revolutionary Movements. Melbourne, New York Ediciones Tricontinental - Ocean Press.

PITMAN, T., \& STAFFORD, A. (2009). Introduction: transatlanticism and tricontinentalism. Journal of Transatlantic Studies, No 7, Vol. 3, pp. 197-207.

POZZI, Pablo (2001). Por las sendas argentinas... El PRT-ERP. La guerrilla marxista. Buenos Aires: Eudeba.

PRASHAD, Vijay (2007). The Darker Nations: A People's History of the Third World. New York: New Press.

PRASHAD, Vijay (2013). Las Naciones pobres. Una posible historia global del sur. Barcelona, Península. 
PRIESTLAND, David (2010). Bandera Roja. Barcelona: Crítica.

RATLIFF, William E. (1986). Castroism and Communism in Latin America, 19591976. Washington, D.C.: American Enterprise Institute-Hoover Institution.

REGALADO, Roberto (2011). La Revolución Cubana: Anfitriona de la Conferencia Tricontinental. La Jiribilla. Revista de Cultura Cubana. La Habana Disponible en http://todolospueblos.ning.com/profiles/blogs/brdiv-idsectionmaindiv Acceso: 16 jun. 2020.

REY TRISTÁN, Eduardo (2005). La Organización Latinoamericana de Solidaridad (OLAS) y la polémica sobre las formas de la revolución latinoamericana. El caso uruguayo. En: GUTIÉRREZ ESCUDERO, Antonio y LAVIANA CUETOS, María Luisa (Coord.), Estudios sobre América, siglos XVI-XX: Actas del Congreso Internacional de Historia de América, AEA, Murcia, pp. 1693-1706.

RODRIGUEZ OSTRIA, Gustavo (2011). Luis Faustino Stamponi, una vida en la lucha armada 1962-1976. Lucha Armada en Argentina Anuario 2011, Año 7, Buenos Aires: Ejercitar la memoria editores, p. 214-232.

ROSENBLUM, Beth Tamar (2005). OSPAAAL posters and the Cuban vanguard aesthetic. Tesis de Maestría. Los A'ngeles: University of California.

ROT, Gabriel (2000). Los orígenes perdidos de la guerrilla en la Argentina. La historia de Jorge Ricardo Masetti y el Ejército Guerrillero del Pueblo. Buenos Aires: Ed. El Cielo por Asalto.

ROUQUIÉ, Alain (1994 [1987]). América Latina, Introducción al extremo occidente. México: Siglo XXI.

ROUQUIÉ, Alain y SUFFEN, Stephen (1997). Los militares en la política latinoamericana desde 1930. En: BETHELL, Leslie (ed.). Vol. 12. Barcelona: Cambridge University Press-Crítica, pp. 281-337.

SANTUCHO, Julio (2004). Los últimos guevaristas, la guerrilla marxista en la Argentina. Buenos Aires: Vergara.

SASSON, Donald (2001). Cien años de socialismo. Barcelona: Edhasa.

SECRETARÍA GENERAL DE LA OSPAAL (1966). Primera Conferencia Tricontinental. La Habana: OSPAAAL.

SEIDMAN, Sarah (2012). Tricontinental Routes of Solidarity: Stokely Carmichael in Cuba. Journal of Transnational American Studies, 4 (2), en http://escholarship.org/uc/item/0wp587sj. Acceso en: 18 feb.2020.

TORRES MOLINA, Ramón H. (1968). La lucha armada en América Latina. Buenos Aires: Tercer Mundo.

TRETO, C. A. (2010). La Revolución Cubana y su influencia sobre la Izquierda latinoamericana y caribeña. Pensamiento Propio, No 32, pp. 161-185.

VARELA, Alfredo (1966). Un gran acontecimiento: la Tricontinental. Cuadernos de Cultura, $\mathrm{n}^{\circ} 79$.

VERGARA ÁLVAREZ, Marco (2015). La Constituyente Revolucionaria. Historia de la fundación del MIR chileno. Santiago de Chile: LOM Ediciones.

VILLAÇA, Mariana (2017). Cuba e a esquerda uruguaia: o encontro da OLAS (Organización Latinoamericana de Solidaridad, 1967) nas páginas de Marcha. Projeto História, No 59, abr.-jul., pp. 309-336.

WEISZ, Eduardo (2004). El PRT-ERP: Nueva Izquierda e Izquierda Tradicional. Cuadernos de Trabajo, $\mathrm{N}^{\mathrm{o}}$ 30. Buenos Aires: Ed. del Instituto Movilizador de Fondos Cooperativos.

WICKHAM-CROWLEY, Timothy P. (1992). Guerrillas and revolution in Latin America: A comparative study of insurgents and regimes since 1956. Princeton: Princeton University Press. 
WRIGHT, Frances (1995). The Tricontinental Conference of 1966 and Cuba's Policy of internationalism (1965-1970). Thesis (M.A.), University College, University of London.

YOUNG, Robert J. C. (2001). Postcolonialism: An Historical Introduction. Oxford, Blackwell.

YOUNG, Robert J. C. (2005). Postcolonialism: From Bandung to the Tricontinental. Historein, $\mathrm{N}^{\circ}$ 5, pp. 11-21.

YOUNG, Robert J. C. (2018). Disseminating the Tricontinental. En: CHEN, Jian et al. The Routledge handbook of the global sixties: between protest and nationbuilding. New York: Routledge, p. 521-523.

Artigo recebido em 30 de maio de 2020.

Aprovado em 02 de julho de 2020.

DOI: 10.12957/intellectus.2020.52504 